Wehind the sternum, accompanied by a slight cough but by no pain. This soon passed off, its occurrence being completely forgotten. Early in the following January he had a somewhat severe attack of "influenza," followed shortly afterwards by a relapse, both attacks being accompanied by severe coughing and a slight amount of expectoration of thick yellowish muco-purulent material. During the relapse he suddenly developed aphonia for several days, preceded by slight huskiness of the voice, but unaccompanied by any pain. The cough and slight muco-purulent expectoration, however, continued and in March, 1902, he had an attack of dry pleurisy over the outer aspect of the left lower lobe. On recovering from this he went to the country in the hope of hastening convalescence, but while there he was much troubled by severe attacks of coughing. The cough was dry and hard and expectoration was very scanty, but later it became somewhat more abundant. It was especially troublesome at night, often awakening the patient from sleep, and was accompanied by a feeling of irritation behind the upper part of the sternum. He also noticed that these attacks of coughing were brought on by the act of stooping, and on these occasions be sometimes brought up considerable quantity of thin whitish sputum. In July and August he went for a six weeks' sea voyage and improved considerably in general health, the cough and thick mucopurulent expectoration, however, continuing unabated. These symptoms remained unchanged until Friday, Jan. 30th, 1903, when he had a sudden hæmoptysis while walking along the street, preceded by some coughing. He remained in bed during Saturday and Sunday and on Monday morning he again went out, but owing to a recurrence of the hæmoptysis had to return home. Shortly afterwards, while lying quietly in bed, he felt a "sort of obstruction" in the chest and coughed up a large mouthful of bright red clotted blood. In this he felt something hard, which on examination proved to be the fang of an upper molar tooth with a large cavity at its upper end the edges of which were so sharp and ragged that it must have caused considerable damage to the tissues in which it had lain imbedded for over a year. I saw the patient last October for my father, Dr. George Dickson, E linburgh, and neither of us for a moment suspected that the case was other than one of early phthisis, the patient at that time dating the commencement of his illness from the attacks of influenza in January, 1902, and having entirely forgotten the occurrence of the slight cough and expectoration after the extraction of his teeth in the preceding December. He was also seen by a consulting physician in Edinburgh who had his sputum examined for tubercle bacillus with negative results. The case is one of considerable interest to the dentist as well as to the physician and conveys to both a lesson worthy of remembrance.

Edinburgh.

\section{A CASE OF TYPHOID FEVER WITH PROLONGED} INCUBATION.

BY W. Norwood EAST, M.D. LoND., M.R.C.S. ENG, L R C.P. LOND.,

DEPUTY MEDICAL OFFICER, H.M.'S CONVICT PRISON, PORTLAND.

THE following case of typhoid fever appears worthy of recording, having an incubation period of at least 141 days. The ratient was a convict and during the whole of this period was in H.M.'s prisons under medical supervision, and although the incubation period may have been longer than that stated it can be proved to be of at least that duration. The events preceding the convict's reception to this prison, which are of importance, are as follows. Sentenced by military court-martial in South Africa to a term of penal servitude, he was sent to Pretoria a prisoner and then to Cape Town, where he arrived about March 2nd, 1902. Seven days later he embarked for Southampton, arriving on April 1st. He then passed a few days in a military prison and was received at H.M.'s prison, Lewes, on April 221st. The medical papers of the patient to which I have access are those which accompanied him in the civil prisons and date from his reception into Lewes prison; the dates previous to this are only approximate, being furnished by the patient's memory. On his reception into Lewes prison he stated that he had not suffered from any special illness and that during the whole period of his detention there he was in perfect health. On August 25th he was transferred to H.M.'s convict prison, Portland, likewise in perfect health, well developed, and muscular; his height was six feet and half an inch and his weight was 182 pounds. He was set to work in the blacksmiths' shop. On Sept. 1st he was admitted to hospital; the outer side of the left foot and ankle were inflamed, having been chafed by an ill-fitting boot. He was discharged well on the 8th. Four days later, on the afternoon of Sept. 12th, he was readmitted to hospital, cornplaining of headache and shivering. On examination his pulse was rapid and his temperature was $102^{\circ} \mathrm{F}$., rising in the evening to $104^{\circ}$; he had headache and slight bronchial catarrh, evidenced by occasional rhonchus; the abdomen appeared to be normal ; the spleen was not palpable and there was no roseola; he had no diarrhoea. The tongue was slightly furred. $\mathrm{He}$ informed me that the day after he left hospital-that is, Sept. 9th-he had not felt well and had gradually been getting worse. On the 17th three rose spots were found on the trunk. Typhoid fever was definitely diagnosed and this opinion was confirmed by the Widal reaction. On the 19th the laboratory report of the Clinical Research Association was received, to the effect that tests made from the patient's serum with dilutions of 1 in 10,1 in 25 , and 1 in 50 gave positive reactions. The patient is now well, having passed through a moderately severe attack of typhoid fever with relapse; he had occasional retention of urine and at one time signs of cardiac failure caused anxiety ; "tender toes," with signs of a local neuritis, lasted for a few days, but the cold bath treatment had not been used.

As soon as the diagnosis was made it befell one to endeavour to trace the origin of the attack. Dr. W. A. Dow, medical officer of Lewes prison, reported that there was no typhoid fever in that prison and further kindly reported (Dec. 19th) that the medical officer of health of Lewes had had no case notified since March 20th. At Portland prison there had been no typhoid fever for some years and Dr. D. J. Lawson, medical officer of health of Portland, kindly reported that no case had been notified to him for six months before our patient was attacked. It has been an isolated case and so could not have been due to diet, all of which, except water, milk, and cheese, is cooked before being served. Had it been so with a convict population of over 700 some other case would certainly have occurred. The result of a bacteriological examination of the milk- and water-supply carried out at the Government laboratories was negative. It was therefore impossible for infection to have taken place at either this or Lewes prison. It transpired that on the journey from the latter to this prison, the prisoners being transferred, the patient and three other convicts were given a glass of water to drink at Weymouth station. Could this have caused the infection? The three other convicts have remained in perfect health and Dr. T. H. Jones, medical officer of health of Weymouth, kindly informed me that no case of typhoid fever was notified to him in July, August, or September. The patient could not, therefore, have been infected by this glass of water. It is obvious that infection took place at some date previous to reception into Lewes prison. The patient himself considers that infection took place at Pretoria, but of course this is only a supposition; there was little illness on the ship in which he came to England and his kit was used only by himself. This case is reported with the permission of the Directors of Convict Prisons.

Portland Prison Hospital.

\section{CASES OF ASSOCIATED PNEUMONIA AND PSEUdO.} DIPHTHERIA.

BY JOHN REID, M.D. ABERD.

IT is well known that various cocci, more particularly streptococci, staphylococci, and pneumococci, are almost always found associated with the Klebs-Löfller bacilli in diphtheria and it is also recognised that several morbid conditions are attended with the formation of membrane or exudate more or less resembling that of diphtheria but entirely independent of the Klebs-Löffler bacillus. The organisms present in the last-mentioned class of cases are streptococci, staphylococci, diplococci, and the bacilli of pseudo-diphtheria. These bacilli resemble the KlebsLöffler bacilli to some extent but can be distinguished from 
them by a variety of tests. The following cases are interesting as examples of pseudo-diphtheria preceding or following an attack of pneumonia.

CASE 1.-The patient was a boy, six years of age, who suffered from pneumonia accompanied with croupy spasmodic cough, which persisted until after the lapse of 14 days he had an attack of measles running a normal course and attended with but slight tonsillitis. After the measles he had another attack of pneumonia which cleared up in a few days. The entire pharynx was subsequently covered with a dense grey membrane which disappeared after 24 hours. No diphtheria bacilli were found in it but only cocci. There was otorrhoea preceding and following the attack of measles.

CASE 2.-The patient was a man, aged 37 years, who suffered from pneumonia which was followed by rheumatism. While abroad he bad contracted dysentery and his bowels were washed out by enemata on account of constipation. His tonsils were slightly affected; a membrane identical with that presented in Case 1 was formed on the pharynx and disappeared within 24 hours, leaving small ulcers. This false membrane, unlike that of diphtheria, was noncontagious.

CASE 3.-The patient was a girl, aged six years, a swab from whose throat gave indications of the pseudo-diphtheria bacillus when examined at the Jenner Institute by request of the Wandsworth sanitary authority. Bronchitis followed.

CASE 4. - This patient was a sister of the preceding one, was similarly affected, and had a sharp attack of pneumonia six days afterwards. A memorandum from the medical officer of health stated that such cases "end in recovery and are not followed by sequelæ."

Southfields, S.W.

\section{atedical Societies.}

\section{ROYAL MEDICAL AND CHIRURGICAL SOCIETY.}

\section{Latent Empyema in Infants.}

A MEETING of this society was held on Feb. 24th, $\mathrm{Mr}$. ALFRED WILLETT, the President, being in the chair.

Dr. S. VeRe PEARSON read a paper on Latent Empyema in Infants. He said that empyemata were latent in infants sometimes because of the meagreness of pulmonary symptoms, or an empyema cavity might be overlooked because it was the second of two such cavities. Besides these latent empyemata there was another variety of empyema which was particularly likely to be overlooked and it was with this varitty that the present paper cealt. The cas es belonging to this group were characterised by the occurrence of a small sacculated $\epsilon$ mpyema giving rise to progressive wasting and anæmia and to secondary complications of a grave nature. The onset usually was gradual and the course of the disease was long. An irregularly raised temperature with few symptoms pointir g to disease of the respiratory system was common. The physical signs in an uncomplicated case were not well marked, and this paucity of physical signs depended on the size chronicity, and site of the empyema. The commonest situation was at the extreme posterior base in the vertebral groove. Here ill-defined signs were often obscured by the liver or the stomach interfering with the normal pulmonary resonance. The signs varied often from day to day and a slight impairment of resonance to percussion was sometime the only sign present. The physical signs in cases with secondary pulmonary complications and with complication other than pulmonary were then dealt with. The differential diagnosis from maras mus de pended on the fact that digestive derangements were common but were not so severe as to account satisfactorily for the progressive deterioration in the general condition of the patient. A continuously and irregularly raised temperature often reaching $103^{\circ} \mathrm{F}$., was not common in chronic wasting children. The diagnosis from tuberculosis was often extremely difficult, but the variability of the signs, the signs themselves, and the long delay of the fatal issue in spite of high fever were points of difference between these cases and the majority of cases of tuberculosis in infants. The differential diagnosis of cases with complications from chronic broncho-pneumonia or from purulen pericarditis and other such conditions arising urimarily or econdarily to diseases other than $\epsilon$ myema $n$ as usually very difficult. The secondary effects were, firstly, indirect or toxæmic, the result of the presence of a localised collection of pus, and gave rise to general symptoms-anæmia, wasting, rise of temperature, and pulmonary complications-and locally to thickening of the pleura and fibrosis of the lung: and secondly, direct or bacterial, the result of the spread of the infective agent either locally or by the blood, giving rise (1) locally to purulent pericarditis (and peritonitis) and (2) by blood infection to purulent meningitis, peritonitis, arthritis, and other pyæmic abscesses (and pericarditis). The prognosis was bad; the majority of patients died. The cause of death was usually one of the serious complications, those belonging to the bacterial group. This high mortality depended partly upon the infrequency of correct diagnosis but also partly upon the difficulties of treatment. The questions to decide with respect to treatment were when to explore, where to explore, and how often. Much depended upon the certainty of the diagnosis and the progress of the case. The advisability of exploratory rib resection must be considered in certain circumstances. Six illustrative cases. of the condition were quoted.

Dr. F. DE HAVILLAND HALL said that the paper drew attention to a class of cases which were frequently overlooked. He himself always feared the possibility of missing a small empyema and indorsed the opinion of Dr. Pearson that it was only by receated examination of the chest in these cases that such an error was to be avoided. With regard to the interlobular forms of empyema he considered that diagnosis was impossible, for in many of these ouses there was only a thin layer of pus between the lobes of the lung. The diagnosis was easier in the basal cases and should always be completed by the insertion of the exploring needle. He alluded to a case in which in a debilitated child after pus bad been withdrawn from the chest and a rib had been resected the child had died apparently as the result of the operation. He considered it advisable in doubtful cases to make many explorations with the needle and he did not think the insertion of the needle gave rise to much pain. He alluded to the advantages to be gained by the use of the $x$ rays in some cases and quoted a case in which this method of diagnosis had been of the greatest advantage. He asked Dr. Pearson if albumose had been present in the urine of any of his cases.

Dr. H. S. French mentioned the diagnostic value of the presence of leucocytosis in differentiating cases of empyema from those of tuberculosis. He asked Dr. Pearson if examination of the blood had been made in his cases.

Dr. G. A. SUTHERLAND said that the diffieulty in diagnosis of the folm of case described in the paper was very great. He thought that the term "latent" had been used in the paper to embrace more than one class of case. The only forms of case to which he would apply the term "latent" were those cases in which on careful examination no pbysical signs could be discovered $\mathrm{He}$ considered that repeated exploration in cases in which pus was suspected was advisable and that in those cases in which there was reason to suspect its presence resection of a portion of a rib should be performed and every part of the lung could then be explored.

Dr. F. E. BATTEN said that he did not think it was possible to make the complete exploration of the lung after the resection of a rib suggested by Dr. Sutherland, for in these cases owing to their chronicity the pleural aobesions were considerable and little was gained unless the cavity of the empyema was opened. He doubted if the presence or absence of leucocytosis was of much diagnostic value and quoted a case in which there was no leucocytosis but at the necropsy an empyema was found. He attached considerable diagnostic importance to the history of an acute or rapid onset in these cases. He asked Dr. Pearson if any other organism except the pneumococcus had been found in his. cases.

Dr. H. W. G. MACKENZIE thought that in most cases there was a histery of acute onset. He was of the opinion that exploratory puncture was often unsatisfactory and that resection of a rib should be done in any doubtful case, and he described two cases in which exploration had failed to find pus but on resection of a rib pus had been found and evacuated.

Dr. G. Newton PITt referred to cases of empyema in which the temperature was normal or subnormal throughout the whole course of the disease. He thought that in doubtful cases some aid might be obtained by pinching up the skin on the two sides of the chest, when it would be found that the 